eISSN 2444-7986

DOI: http://dx.doi.org/10.14201/orl201673.14853

Carta al director

\title{
NOTA DEL EDITOR. GESTIÓN DEL PROCESO EDITORIAL Y FORMACIÓN PERMANENTE
}

\author{
Editor's note. Editorial process management and permanent training \\ José Luis PARDAL-REFOYO \\ Director de Revista ORL \\ Correspondencia: jlpardal@usal.es
}

Fecha de Publicación: 3 de julio de 2016

Conflicto de intereses: Los autores declaran no tener conflictos de intereses

Imágenes: Los autores declaran haber obtenido las imágenes con el permiso de los pacientes

Política de derechos y autoarchivo: se permite el autoarchivo de la versión post-print (SHERPA/RoMEO)

Licencia CC BY-NC-ND. Licencia Creative Commons Atribución-NoComercial-SinDerivar 4.0 Internacional

๑) Universidad de Salamanca. Su comercialización está sujeta al permiso del editor

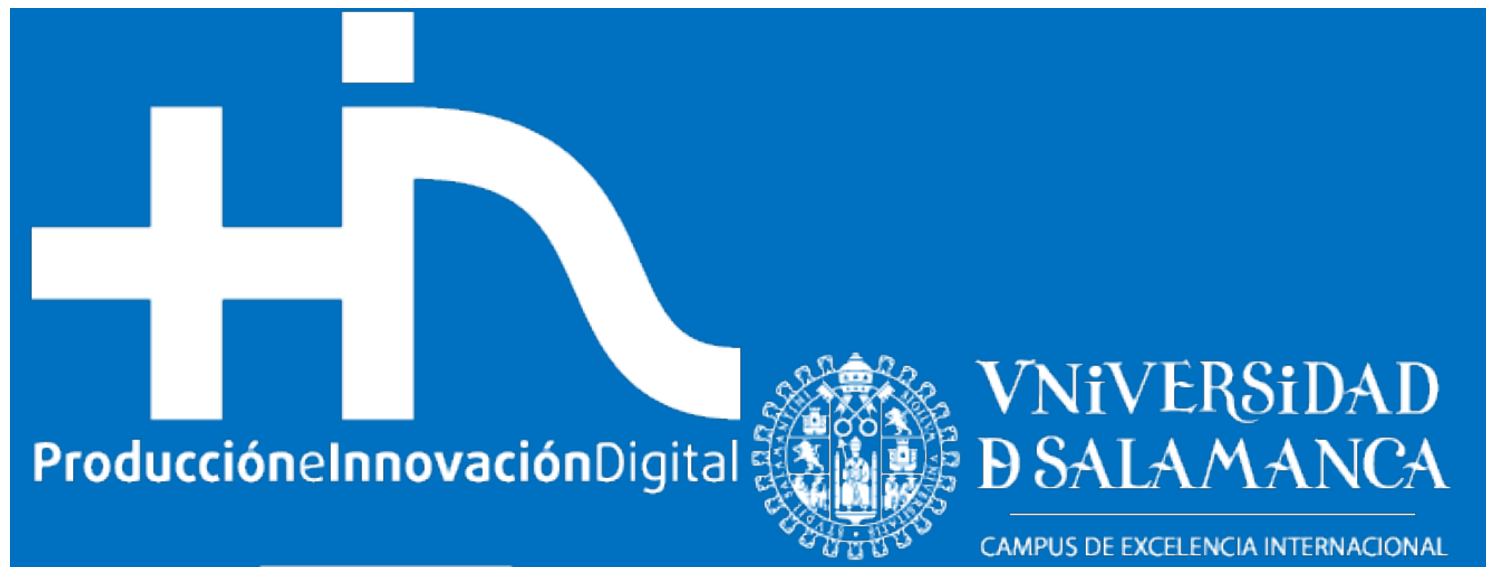

El pasado 28 de junio asistimos a una jornada de formación de introducción para la utilización Journal Systems- en el aula de informática de las herramientas Moodle y OJS -Open del edificio multiusos del Servicio de Producción e Innovación Digital de la Universidad de 
Salamanca a cargo de Juan Ramón Manzanares Serrano y Manuel Martín Mohedano respectivamente, de la Unidad de aprendizaje digital.

Este es un resultado más de la colaboración entre la Universidad de Salamanca y la Sociedad Otorrinolaringológica de Castilla y León, Cantabria y La Rioja en el marco del convenio de colaboración firmado con el Vicerrectorado de Internacionalización ${ }^{1}$ —http://usal.es/node/902formándose un grupo de trabajo estable en el que están representadas la Universidad de Salamanca (Servicio de Bibliotecas https://bibliotecas.usal.es-, Ediciones Universidad de Salamanca -https://eusal.es- y Servicio de Producción e Innovación Digital https://in.usal.es-) y la Sociedad Otorrinolaringológica de Castilla y León, Cantabria y La Rioja. El nexo de unión es Revista ORL.

El grupo va funcionando desarrollando cada cual de forma natural sus funciones.

Además de procurar mantener dos actividades formativas presenciales al año -en marzo y en septiembre-, desde el principio hemos buscado mantener un sistema de actividad formativa permanente que permita la participación de todos los implicados en la gestión editorial, y aquí pensamos en el enriquecimiento hispanoamericano. Las tecnologías de la comunicación permiten este objetivo e instituciones como la Universidad de Salamanca facilitan sus medios tecnológicos.

Desde la primera conversación con Juan Manzanares esta idea quedó clara y el primer objetivo ha sido facilitar la formación en las dos herramientas que vamos a utilizar: el sistema Moodle que utiliza Studium y el sistema de gestión editorial OJS utilizado por Revista ORL (Ediciones Universidad de Salamanca).

Juan Manzanares ofreció una detallada introducción para el manejo de la herramienta Moodle de Studium. Esta herramienta supone una revolución en la enseñanza puesto que permite gestionar todas y cada una de las necesidades tanto formativas como administrativas. El potencial de esta herramienta en interacción con Revista ORL apenas podemos ahora intuirlo.

Posteriormente Manuel Mohedano desarrolló las etapas del proceso editorial con OJS y la asignación de tareas a los distintos agentes que intervienen en él (autores, editores, revisores, correctores, maquetadores). Para nuestros lectores y seguidores el sistema OJS es conocido puesto que es el que se utiliza en la gestión de Revista ORL. En esta segunda actividad de la mañana estuvieron presentes editores de otras revistas publicadas por Ediciones Universidad de Salamanca de distintas facultades y departamentos -Filosofía, Casa Museo Unamuno, Historia Medieval, Moderna y Contemporánea, Informática y Automática, Ciencias, Educación-.

Se cumplieron con creces nuestras expectativas porque esta formación básica podremos practicarla, completarla y aplicarla.

A partir de ahora utilizaremos e integraremos los proyectos de Revista ORL y la formación permanente online.

Son dos las áreas en las que Revista $O R L$ debe participar como agente activo: su principal objetivo en la gestión de la información generada a través de los documentos publicados — con lo que conlleva de publicación y visibilidad-y la formación continuada dentro de su ámbito y objetivos —otorrinolaringología, documentación y metodología de investigación-. Ambas funciones van intrínsecamente unidas puesto que la publicación de los informes de investigación es una forma tradicional de transmisión del conocimiento y, para los lectores, una de las formas de adquirir conocimiento y de formación permanente.

Pero las tecnologías de la información y de la comunicación nos permiten ir más allá con el mismo esfuerzo inicial. Por eso se va alejando la idea de la revista impresa clásica y debemos ir hacia un modelo de comunicación integral que incorpore, además del texto, las imágenes, el hipertexto y los hiperenlaces, otra información complementaria que el autor desee hacer llegar al lector en forma de vídeo, presentaciones interactivas, videoconferencia, modelos de autoevaluación y además establecer sistemas mediante los que los lectores puedan complementar la información del artículo aparte del modelo de la clásica «carta al director», la citación del artículo o los «me gusta» o «compartir» de las redes sociales.

\footnotetext{
1 MERLO-VEGA, José Antonio; FERRERASFERNÁNDEZ, Tránsito. Colaboración Bibliotecas de la USAL y Sociedad Otorrinolaringológica de Castilla y León, Cantabria y La Rioja. Revista ORL, Salamanca, v. 7, n. 1,

p. 65-66, ene. 2016. ISSN 2444-7986. Disponible en: $<$ http://revistas.usal.es/index.php/2444-

7986/article/view/orl201671.13875>. Fecha de acceso: 03 jul. 2016 doi:10.14201/orl201671.13875.

(c) Ediciones Universidad de Salamanca / CC BY-NC-ND [186]

Rev. ORL, 2016, 7, 3, pp. 185-187
} 
A partir de ahora los autores podrán elegir si desean que su artículo forme parte de un programa de formación - bien sea porque desarrolle un aspecto de alguna actividad formativa en activo o bien porque desean crear una actividad formativa nueva-. De este modo el artículo formará parte básica de la actividad formativa.

Por otra parte cualquier actividad formativa que se cree deberá tener una documentación escrita básica que obligatoriamente será publicada en Revista ORL antes de dar comienzo la actividad.

Las actividades formativas se desarrollarán a través de Moodle y aquí los autores, además del documento básico previamente editado, podrán añadir vídeos, textos complementarios, presentaciones gráficas y establecer interacción con los alumnos matriculados (lectores)

Iremos haciendo camino.

\section{AGRADECIMIENTOS}

A Juan Manzanares que ha comprendido el interés del proyecto y organizó esta doble actividad. A Manuel Mohedano que nos aclaró dudas sobre OJS y nos tranquilizó al saber que contamos con él. A Ángel Redero que nos tutela y apoya el proyecto de Revista ORL.
BIBLIOGRAFÍA

Merlo-Vega JA, Ferreras-Fernández T. Colaboración Bibliotecas de la USAL y Sociedad Otorrinolaringológica de Castilla y León, Cantabria y La Rioja. Rev ORL. 2016;7(1):65-66. Disponible en: $<$ http://revistas.usal.es/index.php/24447986/article/view/orl201671.13875>. [Citado el 2 de julio de 2016].

\section{ENLACES RELACIONADOS \\ Documentación sobre OJS: http://ser- vinv02dep.der.usal.es/ojs/documentacion.}

Ediciones Universidad de Salamanca: http://www.eusal.es/.

Open Journal Systems. OJS: https://pkp.sfu.ca/ojs/.

Recursos OJS en español / Public Knowledge Project: https://pkp.sfu.ca/recursos-ojs-en-espanol/.

Revista ORL: http://revistas.usal.es/index.php/2444-7986/index.

Servicio Producción e Innovación Digital. Universidad de Salamanca: http://in.usal.es/.

Studium plus: https://moodle2.usal.es/. 